\title{
Prenatal antidepressant use and risk of autism
}

\author{
(C) $(\mathbb{N} \Theta$ OPEN ACCESS \\ Should be viewed through the kaleidoscope of possible causes of autism
}

\section{Diana E Schendel professor MSO}

Lundbeck Foundation Initiative for Integrative Psychiatric Research, iPSYCH, National Centre for Register-based Research, Aarhus University, Aarhus, Denmark

Although the causes of autism spectrum disorder are largely unknown, among the first clues were observations of greater than expected aggregation of psychiatric disorders in families of children with autism. Such patterns have been quantified in population based risk estimates for autism spectrum disorder associated with family histories of childhood and adult onset psychiatric conditions. ${ }^{1-3}$ Molecular genetic studies are also beginning to show a complex genetic architecture underlying autism spectrum disorder and probably overlapping with other psychiatric and neurodevelopmental conditions. ${ }^{45}$ Compelling evidence also points to the importance of non-heritable factors, especially arising in utero, contributing to the risk of autism, possibly directly or through genetic or epigenetic mechanisms. ${ }^{3-7}$ In addition, autism is phenotypically heterogeneous with regard to behavioural, cognitive, developmental, and medical characteristics, which could reflect diverse causes. ${ }^{8}$ Together, these core features fuel the research expectation that multiple pathways lead to autism spectrum disorder. The findings of the linked paper by Rai and colleagues (doi:10.1136/bmj.j2811) ${ }^{9}$ should be viewed through these complex features.

Their study adds to at least 15 research studies in the US, Canada, and the Nordic countries, as well as meta-analyses since 2010, that investigated the risk of autism spectrum disorder associated with maternal use of antidepressants during pregnancy. ${ }^{9-11}$ The unanswered question about the role of confounding by underlying maternal psychiatric illness in the observed association between maternal antidepressant use and autism prompted Rai and colleagues to apply three different analytical approaches designed to strengthen causal inference in observational studies with potential unmeasured confounding: propensity score matching, discordant sibling matching, and paternal negative control analysis. The authors observed about a $50 \%$ increased risk of autism associated with antidepressant use across the main regression analysis and the three refined analyses, although as sample sizes declined in some of the more refined analyses, so did precision and significance of the corresponding risk estimates. Intriguingly, in another innovative step of estimation of risk separately for autism with or without concurrent intellectual disability, increased risk associated with antidepressant use seemed to be confined to the phenotypic subgroup without concurrent intellectual disability.

When the investigators stratified by type of antidepressant, however, the risk for autism spectrum disorder without intellectual disability was higher in offspring of mothers who had taken non-selective serotonin reuptake inhibitor (non-SSRI) antidepressants rather than SSRI antidepressants and also with antidepressants with low or moderate affinity for the serotonin transporter receptor compared with antidepressants with high affinity (low affinity types are often prescribed for more severe or treatment resistant depression). These results are consistent with the one previous report of variation in risk of autism associated with antidepressants with different serotonin transporter affinity. ${ }^{12}$ Overall, the results stratified by type of antidepressant run counter to expectation based on the hypothesised mechanism of risk arising from fetal exposure to serotonergic agents. These results, coupled with risk from antidepressant use that seemed confined to autism spectrum disorder without intellectual disability, a sub-phenotype that might be more heritable, led the authors to acknowledge that they could not firmly conclude that antidepressant use poses a risk for autism spectrum disorder independent of underlying maternal psychiatric illness. The most recent systematic review and meta-analysis of maternal antidepressant use and autism reached a similar conclusion after the authors evaluated the varied analytical efforts to control for confounding for maternal indication in previous studies. ${ }^{10}$

Despite the analytical rigor of the current study, the balance between heritable and non-heritable factors contributing to the association between antidepressant use and autism remains unresolved. Nevertheless, the view of this association through the complex array of factors contributing to autism spectrum disorder is clearer. The apparent difference in risk associated with antidepressant use and autism with or without concurrent intellectual disability is especially informative because it highlights at least one phenotypic subgroup that could be most relevant. Clarification of the phenotypic subgroup to target could lend analytical efficiency to future studies of autism associated with maternal use of antidepressants—studies that must be better 
powered than previous ones and include measures of severity of maternal disease, perhaps more reliable measures of antidepressant use, and, ideally, genetic markers contributing to the risk of autism of relevance to the potential causative pathways involved.

The reassuring study message for clinicians and women who are taking antidepressants and planning pregnancy or who are pregnant was that more than $95 \%$ of women in the study who took antidepressants did not have a child with autism spectrum disorder. Rai and colleagues estimated that even if the association between antidepressant use and autism is causal, and with all other factors equal, then only $2 \%$ of cases would be prevented if no women with psychiatric disorders used antidepressants during pregnancy. ${ }^{9}$ Although such a small risk within a population might seem too high from an individual's perspective, it must be carefully weighed against the substantial health consequences associated with untreated depression.

Competing interests: I have read and understood BMJ policy on declaration of interests and have no relevant interests to declare.

Provenance: Commissioned, not peer reviewed.

1 Daniels JL, Forssen U, Hultman CM. Parental psychiatric disorders associated with autism spectrum disorders in the offspring. Pediatrics 2008;121:e1357-62.

doi:10.1542/peds.2007-229618450879

Grønborg TK, Schendel DE, Parner E. Recurrence of autism spectrum disorders in full and half siblings and trends over time: a population-based cohort study. JAMA Pediatr 2013;167:947-53. doi:10.1001/jamapediatrics.2013.225923959427
3 Sandin S, Lichtenstein P, Kuja-Halkola R, Larsson H, Hultman CM, Reichenberg A. The familial risk of autism. JAMA 2014:311:1770-7. doi:10.1001/jama 2014.414424794370

4 Cross-Disorder Group of the Psychiatric Genomics Consortium. Identification of risk loci with shared effects on five major psychiatric disorders: a genome-wide analysis. Lancet 2013;381:1371-9. doi:10.1016/S0140-6736(12)62129-123453885

5 Robinson EB, St Pourcain B, Anttila ViPSYCH-SSI-Broad Autism Group. Genetic risk for autism spectrum disorders and neuropsychiatric variation in the general population. $\mathrm{Nat}$ Genet 2016:48:552-5. doi:10.1038/ng.352926998691

6 Hallmayer J, Cleveland S, Torres A. Genetic heritability and shared environmental factors among twin pairs with autism. Arch Gen Psychiatry 2011;68:1095-102. doi:10.1001/archgenpsychiatry.2011.7621727249

7 Lyall K, Croen L, Daniels J. The changing epidemiology of autism spectrum disorders. Annu Rev Public Health 2017;38:81-102.

doi:10.1146/annurev-publhealth-031816-04431828068486

8 Levy SE, Giarelli E, Lee LC. Autism spectrum disorder and co-occurring developmental, psychiatric, and medical conditions among children in multiple populations of the United States. J Dev Behav Pediatr 2010;31:267-75. doi:10.1097/DBP.0b013e3181d5d03b20431403

9 Rai D, Lee B, Dalman C, Newschaffer C, Glyn L, Magnusson C. Antidepressants during pregnancy and autism in offspring: population based cohort study. BMJ 2017:358:2811.

10 Kaplan YC, Keskin-Arslan E, Acar S, Sozmen K. Prenatal selective serotonin reuptake inhibitor use and the risk of autism spectrum disorder in children: A systematic review and meta-analysis. Reprod Toxicol 2016;66:31-43. doi:10.1016/j.reprotox.2016.09.01327667009

11 Castro VM, Kong SW, Clements CC. Absence of evidence for increase in risk for autism or attention-deficit hyperactivity disorder following antidepressant exposure during pregnancy: a replication study. Transl Psychiatry 2016;6:e708. doi:10.1038/tp.2015.19026731445

12 Clements CC, Castro VM, Blumenthal SR. Prenatal antidepressant exposure is associated with risk for attention-deficit hyperactivity disorder but not autism spectrum disorder in a large health system. Mol Psychiatry 2015;20:727-34. doi:10.1038/mp.2014.9025155880

Published by the BMJ Publishing Group Limited. For permission to use (where not already granted under a licence) please go to http://group.bmj.com/group/rights-licensing/ permissionsThis is an Open Access article distributed in accordance with the Creative Commons Attribution Non Commercial (CC BY-NC 4.0) license, which permits others to distribute, remix, adapt, build upon this work non-commercially, and license their derivative works on different terms, provided the original work is properly cited and the use is non-commercial. See: http://creativecommons.org/licenses/by-nc/4.0/. 